\title{
Giant taro and its relatives: A phylogeny of the large genus Alocasia (Araceae) sheds light on Miocene floristic exchange in the Malesian region
}

\author{
Lars Nauheimer $^{\mathrm{a}, *}$, Peter C. Boyce ${ }^{\mathrm{b}}$, Susanne S. Renner ${ }^{\mathrm{a}, *}$ \\ ${ }^{a}$ Systematic Botany and Mycology, University of Munich (LMU), Menzinger-Str. 67, 80638 Munich, Germany \\ ${ }^{\mathrm{b}}$ School of Biological Sciences, Universiti Sains Malaysia, 11800 USM, Pulau Pinang, Malaysia
}

\section{A R T I C L E I N F O}

\section{Article history:}

Received 21 July 2011

Revised 11 November 2011

Accepted 6 December 2011

Available online 22 December 2011

\section{Keywords:}

Ancestral area reconstruction

Colocasia

Miocene climatic optimum

Molecular clock

Wallacea

Sundaland

\section{Introduction}

The Malay Archipelago has long attracted the attention of biogeographers because of its outstanding biodiversity, endemism, and complex geological history (Wallace, 1869; Morley, 1998; Lohman et al., 2011). Of particular interest has been to understand the intermixing of ancestrally Laurasian and Gondwanan lineages in this region, and molecular phylogenies combined with molecular clocks now allow a more precise understanding of the direction and timing of such intermixing (Lohman et al., 2011; Richardson et al., 2012). Biogeographic studies of Malesian plant clades utilizing these methods are available for seven groups. These are the stone oak genus, Lithocarpus (Cannon and Manos, 2003), the myrmecophytic Euphorbiaceae genus Macaranga (Bänfer et al., 2006), the Meliaceae tribe Aglaieae (Muellner et al., 2008), the Annonaceae genus Pseuduvaria (Su and Saunders, 2009), the large genera Cyrtandra (Gesneriaceae; Clark et al., 2008) and Begonia (Begoniaceae; Thomas et al., 2011), and the palm genus Livistona (Arecaceae; Crisp et al., 2010). These studies revealed predominant

\footnotetext{
* Corresponding authors.

E-mail addresses: 1.nauheimer@gmail.com (L. Nauheimer), renner@lrz.unimuenchen.de (S.S. Renner).
}

west to east dispersal and diversification after the late Miocene. This general pattern may be explained by the large source region of wet forest west of the Wallace line and a later emergence of landmasses east of the Wallace line, leading to a more frequent colonization from west to east (Richardson et al., 2012).

A plant group that is extremely species-rich in the Malesian region is the Araceae, a family with a relatively extensive fossil record going back to the Upper Early Cretaceous, Paleocene, and Eocene (Friis et al., 2004, 2010; Wilde et al., 2005; Herrera et al., 2008). Among the largest genera in the family is Alocasia, a member of the relatively derived Pistia clade (Renner and Zhang, 2004; Cabrera et al., 2008; Cusimano et al., 2011). Alocasia currently comprises 113 species, with 27 more awaiting description (Nicolson, 1968, 1987; Hay and Wise, 1991; Hay, 1998, 1999; Boyce, 2008; PB unpublished data). The natural range of Alocasia extends from India and Sri Lanka through Indochina to China and southern Japan, the Malay Archipelago and Oceania; a single species is indigenous in Australia (Fig. 1). Several species are commercially important indoor plants, others are cultivated outdoors, such as Alocasia cucullata (Chinese taro), an ethnobotanically important plant throughout Asia, and Alocasia macrorrhizos (giant taro) a tropical ornamental cultivated for its tubers and leaves, used as animal fodder (Weightman, 1989; Mayo et al., 1997). The wild origin of these two species is unknown (Hay, 1999; Boyce, 2008). 


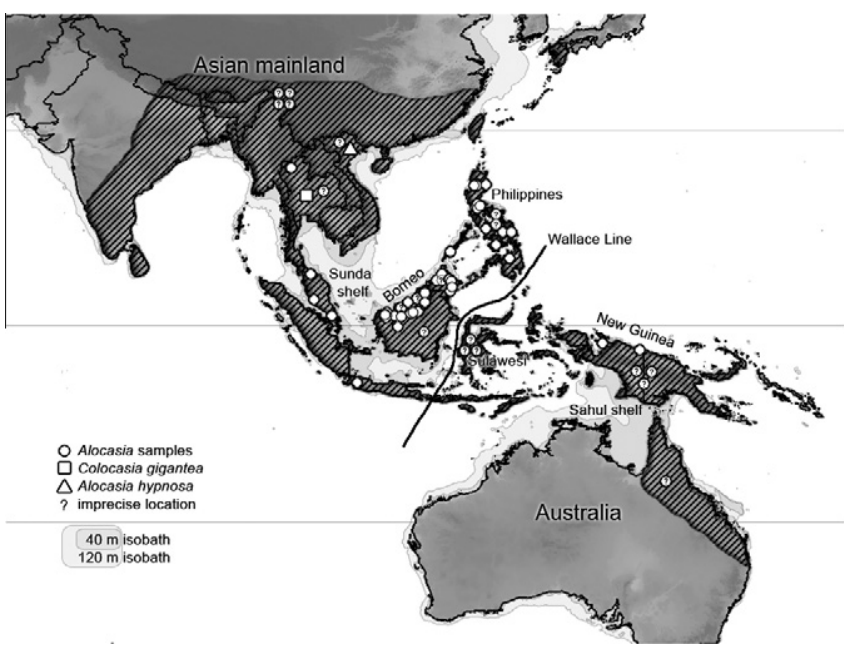

Fig. 1. Map showing the global distribution of Alocasia (shaded area) and origin of samples included in this study. Circles refer to Alocasia samples; circles with a question mark indicate locations without GPS data. The square shows the collection location of the Colocasia gigantea sample, the triangle that of the Alocasia hypnosa sample. The $40 \mathrm{~m}$ and $120 \mathrm{~m}$ isobaths are shown as pale grey outlines.

The typical Alocasia habitat is the understorey of perhumid lowland forest; only a few species grow $>1000 \mathrm{~m}$ altitude or in light-gaps, clearings, or secondary vegetation (Hay and Wise, 1991; Hay, 1998; Boyce, 2008). Growth forms range from small herbaceous to thick-stemmed massive plants with huge leaves (Fig. 2). Seed dispersal is by birds and pollination by drosophilid flies (genus Colocasiomyia) that use the spadices as breeding sites (Ivancic et al., 2005, 2008; Sultana et al., 2006). Little is known about the specificity of Alocasia pollinators or hybridization in nature, but morphologically polymorphic species or species 'complexes' have been suspected as involving hybridization (Hay, 1998).

Molecularly, hybridization can be detected when plastid and nuclear sequences yield different tree topologies, which can point to the maternally inherited plastid genome coming from a different source than an individual's nuclear genome. Given the evidence for widespread hybridization and chloroplast capture in plants (Bänfer et al., 2006; Cristina Acosta and Premoli, 2010; Manen et al., 2010)

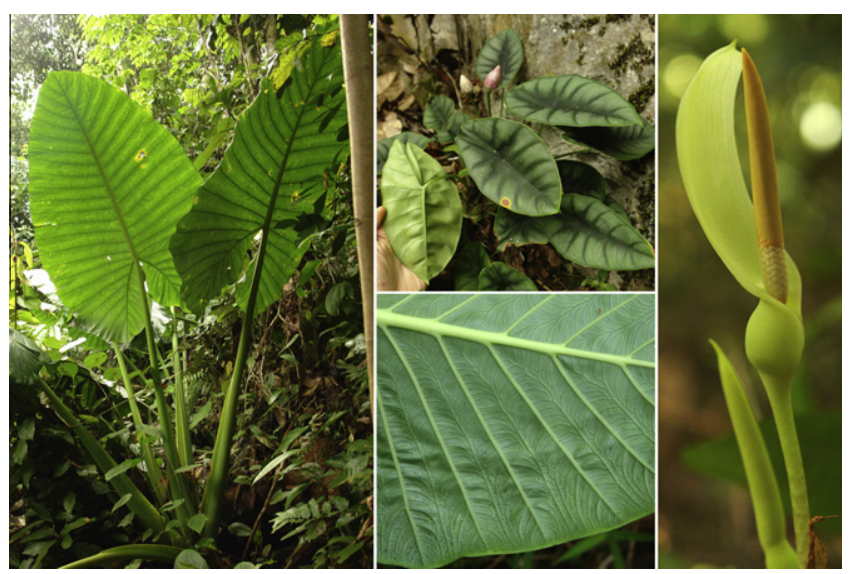

Fig. 2. Representative species of Alocasia. Habit of $A$. robusta at disturbed forest edge, Sarawak, Malaysia (left); habit of A. reversa on limestone rocks, Sarawak, Malaysia (upper middle), inflorescence of $A$. longiloba 'denudata' in rainforest understory in Singapore (right), colocasioid venation on lower leaf surface of $A$. sarawakensis in Sabah, Malaysia (lower middle). it is surprising that only two studies of Southeast Asian plant groups have compared plastid and nuclear histories. In stone oaks, Lithocarpus, Cannon and Manos (2003) found that the nuclear DNA data contained less geographical structure than the plastid data, indicating that gene flow mediated through pollen is less restricted than purely seed-mediated (chloroplast) gene flow, and in Macaranga, Bänfer et al. (2006) documented plastid haplotype sharing by up to seven species and as many as six co-existing haplotypes in a single species.

Here we use both nuclear and plastid sequences and broad geographic sampling of species to address the following questions: (i) Is Alocasia monophyletic and which clade or species in the Pistia group is it most closely related to? (ii) Where do the cultivated species giant taro, A. macrorrhizos, and Chinese taro, A. cucullata, come from? And (iii) Do nuclear and plastid data yield congruent topologies or is there evidence of hybridization? Because of its species diversity and wide distribution range, understanding the biogeography of Alocasia also sheds light on floristic links across the Malesian regions.

\section{Materials and methods}

\subsection{Taxon sampling and number of species}

Of currently 113 Alocasia species, we here sample 71, represented by 78 plants. Table S1 provides a list of the species with author names, geographic origin of material, herbarium vouchers, and GenBank accession numbers for all sequences. Of these species, 32 were named in the past 20 years, and the discovery of new species continues (e.g., Kurniawan and Boyce, 2011). At the moment, 27 species await description once complete flowering and fruiting material is available ( $\mathrm{PB}$, personal collections). Our sampling covers the geographic range and morphological diversity of Alocasia, except for New Guinea, which is underrepresented (Hay and Wise, 1991 recognized five groups there of which our sample includes one). Of the taxonomically problematic species Alocasia longiloba we included 13 accessions (with nine different species names) and of Alocasia robusta (Fig. 2, left photo) three. Leaf material came from herbarium specimens or silica-dried leaf samples (Table S1). Determination of plant material relied on comparison with herbarium material carried out by PB and LN. As outgroups, we included 25 species representing 16 genera of the Pistia clade (Renner and Zhang, 2004; Cabrera et al., 2008; Cusimano et al., 2011), usually the type species of the genus name.

\subsection{Isolation of DNA, amplification, and sequencing}

DNA isolation followed standard protocols. To deduce phylogenetic relationships, we relied on the nuclear phytochrome $C$ gene (phyc), and four plastid loci, the trnL intron, the trnL-F intergenic spacer, the rpl20-rps12 intergenic spacer, and the trnK/matK region. Total DNA from silica-dried leaves was extracted with the NucleoSpin plant kit according to the manufacturer's protocol (Macherey-Nagel, Düren, Germany). Sequencing of the $>2500$ nucleotide (nt)-long trnK marker, amplified in one piece with the primer pair trnK-3914F (dicot) - trnK-16R (Johnson and Soltis, 1994), was problematic. Consequently, we designed new internal primers and amplified the section in four pieces: trnK-3914F - trnK-AR-alo, trnK-19F - trnK-RM-ara, trnK-FM-ara - trnK-1760R-alo, and trnK-1640F-alo - trnK-R1-mono. The new primer sequences are as follows: trnK-AR-alo 5'-CTC TTG AAA GAG AAG CGG ATA TAG-3', trnK-19F 5'-TGT TCT GGC CAT ATC GCA CTA TG-3', trnK-RM-ara 5' AAG ATG TTG ATC GTA AAT AAG AGG-3', trnK-FM-ara 5'-GTT TTG CTG TCA TTA TGG AAA TTC-3', trnK-1760R-alo 5'-TAC CGC TGA AGG ATT TAT TAG GAC-3', trnK-1640F-alo 5'-GGG ACT CAT CTT 
CTG ATG AAG AAA-3', trnK-R1-mono 5'-CAT TTT TCA TTG CAC ACG RC-3'. PhyC was also amplified in two pieces with the newly designed primers: A20F - 748R and 430F - AR: A20F: 5'-CAC TCA ATC CTA CAA ACT GGC-3', 748R: 5'-ACA AGA TCC ATG ACA TTA GGT GAT T-3', 430F: 5' CTC GTG ATG TCT GTC ACA ATA AG-3' and AR: 5'-GAA TAG CAT CCA TTT CAA CAT C-3'. The rpl20-rps12 intergenic spacer was amplified using the primers and PCR conditions described in Renner and Zhang (2004). The trnL intron and trnL-F intergenic spacer was amplified according to Taberlet et al. (1991) with the primer pairs $\mathrm{c}-\mathrm{d}$ and $\mathrm{e}-\mathrm{f}$, respectively. PCR products were cleaned using the NucleoSpin ${ }^{\circledR}$ Extract II kit (Macherey-Nagel, Dueren, Germany), and sequencing reactions were run on an ABI 3130 capillary sequencer (Applied Biosystems), following the manufacturers' protocols. Sequence editing and alignment were carried out in Sequencher 4.7 (Gene Codes, Ann Arbor, Michigan, USA) and McClade 4.0 (Maddison and Maddison, 2000). New sequences generated for this study have been deposited in GenBank (accession numbers in Table S1), and alignments for this study in TreeBASE (submission ID 12182).

\subsection{Phylogenetic analysis}

Individual and combined phylogenetic analyses were performed under likelihood (ML) optimization and the GTR $+\Gamma$ substitution model, using RAxML 7.0.4 (Stamatakis, 2006) and the RAxML-GUI 0.93 (Silvestro and Michalak, 2010). Statistical support was assessed via 100 bootstrap replicates. Throughout this paper, $70-84 \%$ bootstrap support is considered moderate and $85-100 \%$ strong support.

\subsection{Divergence dating}

Dating relied on Bayesian divergence time estimation as implemented in BEAST 1.61 (Drummond et al., 2006; Drummond and Rambaut, 2007). Identical sequences and sequences differing only in nucleotide ambiguities were removed, yielding a matrix of 81 species (56 Alocasia). For the dating runs, we used the $\mathrm{HKY}+\Gamma$ model of substitution, which is an extension of the $\mathrm{K} 80+\Gamma$ model identified as the best fit in jModelTest (Posada, 2008), and a Yule tree prior as the tree model. Runs were repeated under either a strict clock model or a relaxed clock model, the latter with rate variation across branches uncorrelated and lognormally distributed. MCMC chains were run for 16 million in the strict clock model, and for 50 million generations in the relaxed clock model, with parameters sampled every 1600th and 5000th generation, respectively. Tracer (1.50) was used to assess effective sample sizes (ESS) for all estimated parameters and to judge the percentage of burn-in for tree constructions. Trees were combined in TreeAnnotator (1.6.1), and maximum clade credibility trees with mean node heights were visualized in $\mathrm{R}$ (www.r-project.org) with the package phyloch (www.christophheibl.de/Rpackages.html).

For calibration, we used the age of the leaf fossil Caladiosoma messelense from the Messel Formation near Frankfurt, Germany (47-47.5 Ma), which resembles species of Alocasia and Colocasia in its colocasioid leaf venation (Fig. 2). This venation consists of fine veins that branch almost at right angles from the primary lateral veins and arch towards the leaf margin, sometimes fusing to an interprimary collective vein. It occurs in Alocasia, Colocasia, Ariopsis, Remusatia, and Steudnera, but also in the South American genera Caladium and Xanthosoma. The Eurasian origin of the fossil, however, fits better with a placement as a relative of Southeast Asian Araceae. Other members of the Pistia clade, such as the Areae, do not possess colocasioid venation, either due to a loss of the character or because of multiple gains in Alocasia, and the Colocasia clade. To account for the uncertain placement of $C$. messelense in the Pistia clade, we explored the effects of different fossil- cum-topology combinations on the resulting age estimates (Results), always using a normally distributed prior age distribution that had a mean of $47.25 \mathrm{Ma}$ and a standard deviation (SD) of $0.15 \mathrm{Ma}$. This narrow SD is justified by the well-constrained dating of the Messel Formation (V. Wilde, Senkenberg Museum, Frankfurt, Germany, pers. comm., 2009). Additionally, one run was performed without constraining the topology. We also ran an analysis with an empty alignment (the "prior-only" option in BEAST) to compare the posterior parameter values without and with the data. This allows evaluating the influence of prior distributions on the outcome of Bayesian analyses. For absolute ages we relied on the geologic time scale of Walker et al. (2009).

\subsection{Ancestral area optimization}

To infer the geographic history of Alocasia, we used two approaches: Dispersal vicariance analysis (DIVA) in a Bayesian framework, using the S-DIVA (Statistical Dispersal-Vicariance) program in RASP 1.1 (Yu et al., 2010, 2011), and a dispersal-extinction-cladogenesis model (DEC) in a likelihood framework, using Lagrange (Ree et al., 2005; Ree and Smith, 2008). S-DIVA applies the DIVA method of Ronquist (1997) to the multiple trees from a Bayesian analysis, which has the advantage that uncertainties in phylogenetic inference can be taken into account. In contrast, Lagrange uses a likelihood approach that takes into count the branch length of a given tree. As input for S-DIVA we used the BEAST MCMC tree chain obtained under the strict clock model applied to the nuclear data (minus the burn-in of the divergence dating analysis) and the maximum clade credibility tree to plot the results. As input tree for Lagrange we used the same BEAST maximum clade credibility tree. A Python script was created using the online Lagrange configurator. We did not constrain the dispersal probabilities to avoid over-parameterization.

Species distributions were categorized into eight areas: (A) Asian mainland (including Sumatra and Java), (B) Borneo (including the Philippine island Palawan, which geologically belongs to the Sunda shelf), (C) The Philippines, (D) Sulawesi, (E) New Guinea, (F) Australia, (G) Mediterranean area, and (H) Seychelles. In SDIVA, as combined ancestral areas we allowed three combinations: Asia with the Mediterranean area (AG), the Asian mainland with Borneo ( $\mathrm{AB}$ ), and New Guinea with Australia (EF). Lagrange requires connectivity between areas, which we provided by allowing combined ancestral areas of adjacent regions: $A B, A G, A H, B C, B D$, $\mathrm{CD}, \mathrm{CE}, \mathrm{DE}$, and EF. Alocasia spec. nov. BO07, from the Botanical Garden in Bogor has identical nuclear sequences as Alocasia portei and $A$. macrorrhizos. Its reported origin (Sulawesi) could not be verified, and it was therefore excluded from this analysis.

\section{Results}

\subsection{Sequence data}

Four hundred twenty-one sequences were newly generated for this study. The aligned trnL sequences comprised 731 positions, of which we excluded 260 of one poly-T run, two poly-A runs, and a TA tandem array region. The trnL-F alignment comprised 439 nucleotides of which one poly-T run with five nucleotides was excluded. The length of the rpl20-rps12 alignment was 808 nucleotides of which we excluded 22 nucleotides of two poly-A runs and one poly-T run. The trnK/matK alignment included no ambiguously aligned sections and was used in its entirety for a length of 2504 aligned positions. The alignment of the nuclear low copy gene phyC comprised 1074 nucleotides, including four that showed double peaks. These sites were excluded from phylogenetic analyses. 


\subsection{Phylogenetic relationships in the plastid and nuclear trees}

Plastid trees from the four data partitions revealed no statistically supported discrepancies and the sequences were therefore concatenated. Comparison of the combined plastid tree with the nuclear phyc tree, however, revealed topological contradictions. In both trees, species of Alocasia form a strongly supported clade with the exception of Alocasia hypnosa, which in the plastid tree (Fig. 3a) is sister to most of the remaining Pistia clade, but in the nuclear tree is placed more centrally in the Pistia clade (Fig. 3b). For the remaining taxa, both trees reveal the same main lineages: (a) Alocasia plus Colocasia gigantea (indicated by yellow branches in Fig. 3), (b) the Areae clade (Arisaema, Arum, Biarum, Dracunculus, Eminium, Helicodiceros, Lazarum, Pinellia, Sauromatum, Theriophonum, and Typhonium; blue branches in Fig. 3), and (c) the Colocasia clade (Colocasia as to its type species, Ariopsis, Remusatia, and Steudnera; green branches in Fig. 3).

Within core Alocasia (excluding A. hypnosa), the plastid phylogeny shows six geographic clades, numbered and color-coded in Fig. 3a. An Asian mainland clade (clade i shown in green) is sister to a polytomy that comprises a Philippine clade (clade ii shown in purple), a New Guinean clade (iii, yellow), a Bornean clade (iv, blue), another Asian mainland clade (v, green), and a poorly supported clade of Bornean and Philippine species (vi, blue). The position of the sole Australian species of Alocasia, A. brisbanensis, remains unresolved.

The nuclear phylogeny revealed four main clades (labeled A to D in Fig. 3b), which often include species with similar morphological traits. Clade A contains most species of the longiloba group. All have strongly rhythmic growth, thinly membranous cataphylls, and solitary or rather few leaves with often peltate, pendulous blades; however, two Sulawesian species that morphologically are convincingly part of this group are in Clade C. Clade A further contains a group of massive species with syleptic renewal, bi-modular inflorescences, long petiolar sheath, and large, short-lived leaves that all occur in the Indochinese region. Clade B comprises all species with a massive caulescent habit, including species with proleptic renewal growth (e.g., A. robusta) and sylleptic renewal growth (e.g., A. macrorrhizos). Clade B also includes the edible $A$. macrorrhizos and three accessions of $A$. robusta. Clade $C$ contains only species with short-lived leaves and proportionately long petiolar sheaths, including the New Guinean Xenophya species group (Nicolson, 1968), which has hemianatropous or anatropous ovules and a usually persisting spathe limb (Hay and Wise, 1991). Clade D contains small or robust often lithophytic species usually referred to as the princeps group (Alocasia princeps, Alocasia pangeran, Alocasia principiculus, Alocasia wongii, Alocasia ridleyi, Alocasia "inopinata" (P. Boyce, ined.), and Alocasia reversa), characterized by long erect petioles, narrowly triangular leaf blades, the lower spathe constriction occurring well above the sterile interstice between the pistillate and staminate flowers, relatively elongated inflorescences with tapering appendices (Hay, 1998), and the similar scabriuscula group (Alocasia scabriuscula, Alocasia melo, Alocasia reginula, Alocasia kulat, Alocasia reginae, Alocasia chaii, Alocasia infernalis, and Alocasia nebula), characterized by leathery to subsucculent leaves, several to many inflorescences not interspersed by foliage leaves, and the spathe constriction often above the sterile interstice of the spadix (Hay, 1998).

Topological differences between the plastid and nuclear trees were also found in the taxonomically problematic A. robusta and A. longiloba of which our sampling included, respectively, three and 13 accessions (the last with nine species names). In the nuclear tree, 11 of the 13 accessions of the A. longiloba species complex group together (yellow bar in Fig. 3b), while in the plastid tree (3a) they are partly found in clade I, partly in clade iv, and partly in clade $\mathrm{v}$. The three accessions of $A$. robusta group together in the nuclear tree (clade B in Fig. 3b), although the phyC sequences of the two Sabah plants differ from the Sarawak plant in two substitutions. In the plastid tree (Fig. 3a), the Sabah plants have identical sequences, but the plant from Sarawak differs substantially.

\subsection{Divergence time estimation}

Divergence time estimation (Fig. 4) relied on the nuclear dataset because it better reflects bi-parental inheritance. Since the relationships of $A$. hypnosa to the other groups (Alocasia/C. gigantea; the Colocasia clade; and the Areae clade; color-coded in Fig. 3) were not confidently resolved by our data, calibration with the Caladiosoma messelense leaf fossil (Section 2) was applied to 15 possible topologies for these clades. The results (Table S2) show that ages in the Alocasia crown node hardly differed among the 15 trees. The best ESS values were reached with the topology in which the Areae were sister to the remaining taxa, and the topology obtained from an unconstrained run also showed this placement of the Areae. The strict clock model and the relaxed clock model gave estimates for the Alocasia crown that on average differed by $6.16 \pm 0.9 \mathrm{Ma}$, with the relaxed clock model yielding older ages. Mean ages from the strict clock model generally fall inside the 95\% highest posterior density (HPD) intervals of the relaxed model, but the converse is not the case (Table S2). The mean phyC substitution rate was $0.00060 \pm 0.00001$ per site/million years under the strict clock and $0.000055 \pm 0.00003$ under the relaxed clock.

According to the strict clock model, the split between Alocasia and C. gigantea occurred at 24.1 Ma, i.e., the transition of the Oligocene to the Miocene, and Alocasia began diversifying in the MidMiocene (13.5 Ma). Dates are $\sim 1.47$ times older in the relaxed clock analysis, which places the stem of Alocasia in the Mid-Oligocene (29.1 Ma) and its crown in the Early Miocene (19.3 Ma). Exact dates with HPD for biogeographically important nodes are shown in Table S2, and for all nodes in the preferred tree in Table S3.

\subsection{Ancestral area optimization}

Bayesian (S-DIVA) and likelihood-based (Lagrange) ancestral area reconstruction on the nuclear tree yielded mostly congruent ancestral areas except for nodes 24, 26, and 41 (marked in bold in Fig. 4 and Table S3). Node 24 involves the sparsely sampled outgroups Sauromatum and Lazarum. Nodes 26 and 41 are the deepest splits in core Alocasia (i.e., excluding A. hypnosa, which clearly is not a member of a monophyletic genus Alocasia). S-DIVA and DEC both inferred that the split between Alocasia and $C$. gigantea occurred on the Asian mainland, but they differed in the inferred distribution of most recent common ancestor of the Alocasia crown group (node 26): S-DIVA inferred an origin in Asia, Lagrange an origin on Borneo. Both approaches inferred the combined area Sundaland as the second-most probable ancestral region for this node. For node 41, Lagrange inferred an origin on Borneo, while S-DIVA inferred an origin on the Asian mainland. S-DIVA also inferred combined ancestral areas more often than did Lagrange, resulting in the inference of fewer dispersal events by S-DIVA. Of the 54 divergence events in the tree, 18 or 19 involve dispersal events, with the majority dispersals out of Borneo (13 inferred by Lagrange, 11 by S-DIVA), in contrast to only three or four dispersal into Borneo. The Philippines were colonized 4-5 times and are the likely region from which New Guinea and Australia were colonized (node 42 in Fig. 4). Sulawesi was reached once from Borneo and once from the Philippines. Dispersal and divergence events are more or less evenly distributed over time (Fig. 4). 


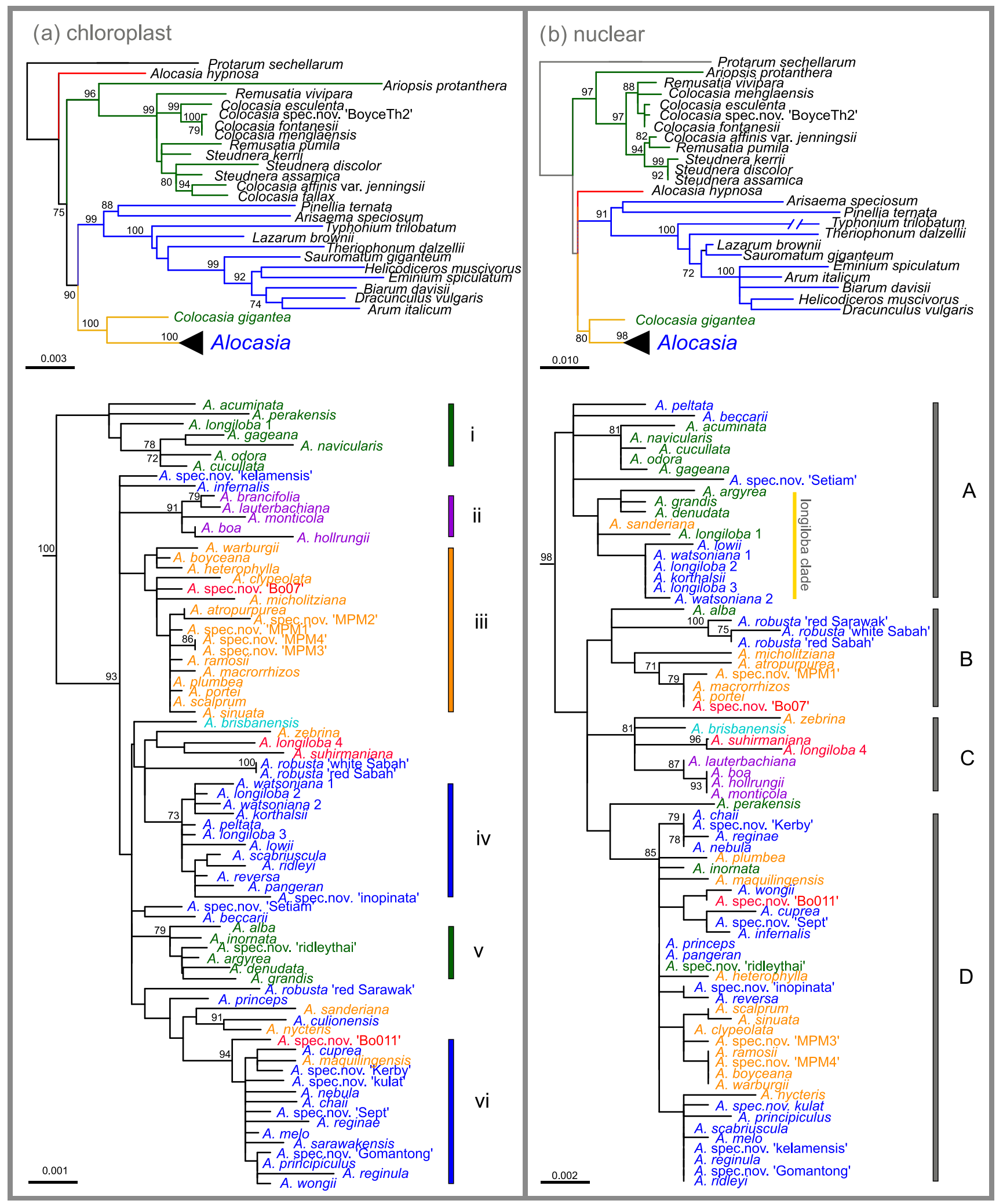

Fig. 3. Maximum likelihood (ML) phylogenies for Alocasia and its outgroups obtained from the plastid DNA data (a) and nuclear DNA data (b). The upper section of each tree shows the outgroups, the lower section the ingroup. Numbers at nodes indicate ML bootstrap support from 100 replicates. Species names are colored according to the origin of the samples; green: Asian mainland, blue: Borneo, orange: Philippines, red: Sulawesi, purple: New Guinea, cyan: Australia. Branch colors indicate the main clades among the outgroups; green: Colocasia clade, blue: Areae clade, red: Alocasia hypnosa. Clades discussed in the text are marked by letters. 


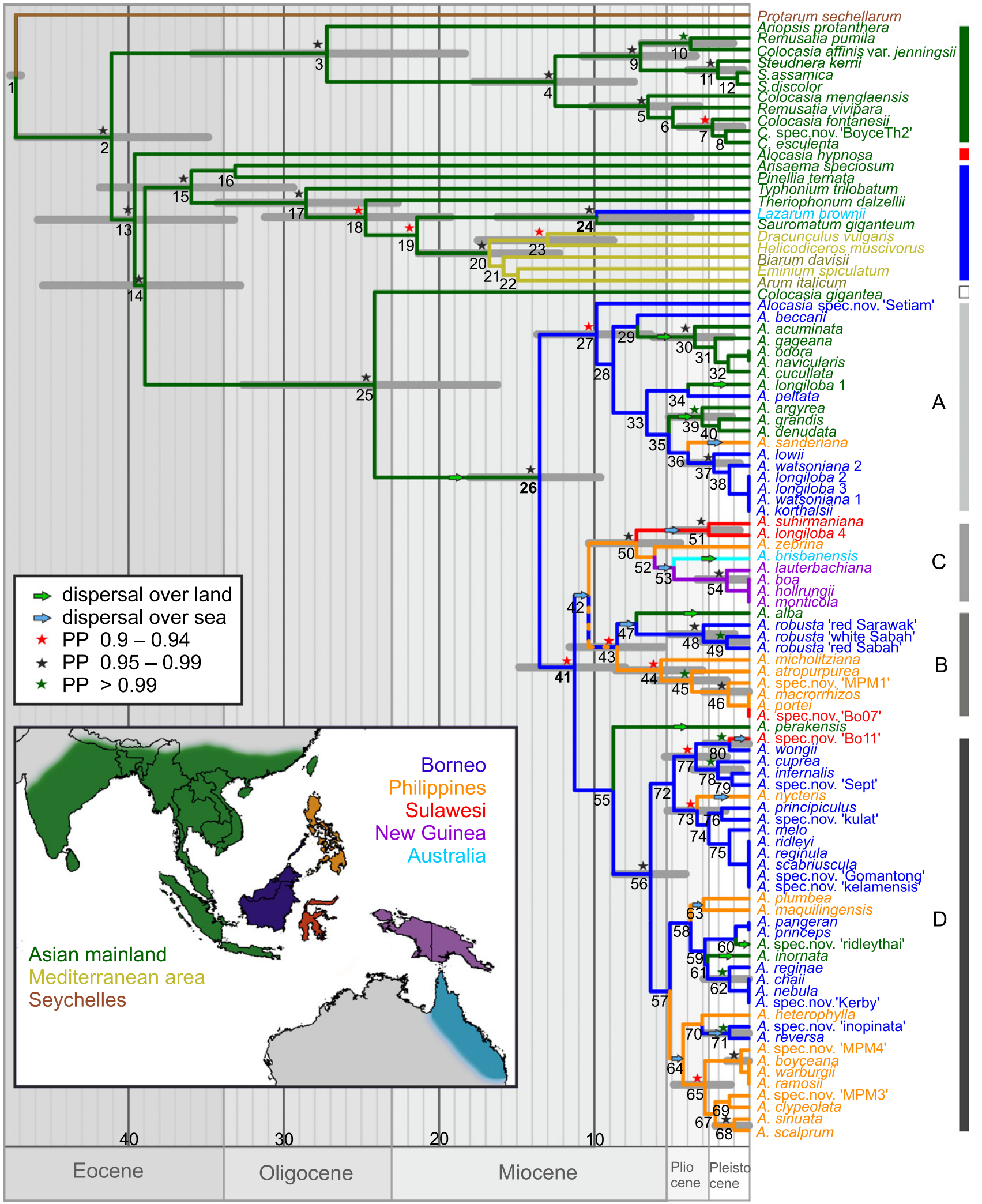

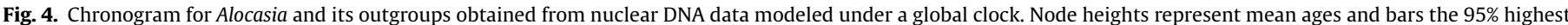

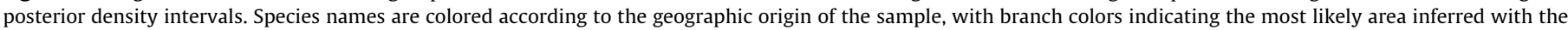

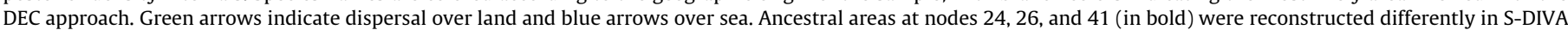

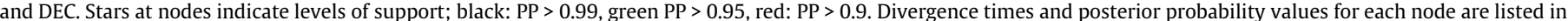
Table S3. Clades discussed in the text are marked by letters. An asterisk $\left(^{*}\right)$ marks accessions with near-identical sequences, that were excluded from dating analyses. 


\section{Discussion}

\subsection{Monophyly and phylogenetic relationships}

The least expected findings of this study probably are that a monophyletic circumscription of Alocasia requires the removal of A. hypnosa and that the closest relative of Alocasia is Colocasia gigantea, while the type species of Colocasia ( $C$. esculenta) groups elsewhere in the phylogeny of the Pistia clade (Fig. 3). Colocasia gigantea occurs naturally from Southwest China, Indochina, and Thailand through Peninsular Malaysia and Sumatra to Java. This large-flowered species was originally described as Caladium giganteum (Blume, 1823), and Schott (1857) then made it the basis of a new genus, Leucocasia, recognizing that it did not fit in Caladium because of its unilocular ovaries with sub-orthotropous ovules. Later, Hooker (1893) transferred the species to Colocasia where it indeed fit well in terms of its placentation and leaf thickness. A few species of Alocasia, for example, A. macrorrhizos, however, also have such leaves. Since the name Colocasia must stay with $C$. esculenta, $C$. gigantea could now either be reinstated as Leucocasia gigantea (as yet another monospecific genus of the Araceae) or it could be transferred into Alocasia.

Alocasia hypnosa, the surprising non-Alocasia discovered here, was described in 2005 from plants collected in southern Yunnan, China, and then cultivated at the Xishuangbanna Botanical Garden (Wang et al., 2005). It has recently also been collected in northern Vietnam. The species is characterized by a purple spathe, numerous long stolons, and seasonal deciduousness and was placed in Alocasia because of its few basal ovules, red colored fruits, and its overall similarity to Alocasia odora. Our data reveal that it is a genetically highly distinct lineage of the Pistia clade, but more loci will need to be sequenced for a secure placement of this species.

\subsection{Incongruence of nuclear and plastid phylogenies, and relationships} in the A. robusta and A. longiloba species groups

Most Alocasia clades in the plastid phylogeny (Fig. 3a) are restricted to a particular geographic region. By contrast, most major clades in the nuclear phylogeny comprise morphologically similar species from the Philippines, Asia, and Borneo (Fig. 3b). The morphological similarities were specified in section 3.2 and mainly concern species of the longiloba group, the scabriuscula group, the princeps group, and the Xenophya group (Nicolson, 1968; Hay and Wise, 1991; Hay, 1998).

The observation that relationships seen in plastid data, which reflect maternal inheritance (and local seed dispersal), correlate with geographic proximity, while those seen in nuclear data correlate more with morphological species boundaries has been made in many other studies (e.g., Soltis and Kuzoff, 1995; Cristina Acosta and Premoli, 2010; Manen et al., 2010; Rautenberg et al., 2010). For South-East Asia, this is the case in stone oaks (Cannon and Manos, 2003) and Macaranga (Bänfer et al., 2006). Where plant species hybridize (even just occasionally), the combination of mostly local seed dispersal and obligate out-breeding (via interplant pollen transport) may lead to the long persistence of the genetic signal left by the hybridization. Such conditions would seem to apply in Alocasia, in which complete temporal separation of individuals' male and female function enforces outcrossing and in which seed dispersal is by understory birds. The Colocasiomyia flies that pollinate Alocasia sometimes visit co-flowering Alocasia species although it is not known whether they can successfully oviposit in more than one species (Toda and Lakim, 2011). Many cultivated species of Alocasia have been crossed, including phylogenetically distant ones (Garner, 2010; L. Garner, Aroidea research, Florida City, Florida, pers. comm., February 2011; A. odora $\times$ A. nyc- teris, A. odora $\times A$. portei, A. macrorrhizos $\times A$. sinuata), suggesting that hybridization may also occur in nature.

The morphologically polymorphic species A. robusta and A. longiloba of which we included several accessions both revealed nuclear/plastid tree discrepancies. The accessions of $A$. robusta from Sabah and Sarawak group together in the nuclear tree (Fig. 3b; clade B), even though phyC sequences of the two Sabah plants differ from the Sarawak plant in two substitutions. In the plastid tree (Fig. 3a), the Sabah plants have identical sequences, but the plant from Sarawak differs substantially and placed apart from the other two. Typical A. robusta (Fig. 2, left photo) has dark red spathe limbs, and mature inflorescences that smell of decomposing meat, suggesting sapromyophilous pollination. A form with white spathe limbs and sweet odor exists in Sabah, where it co-occurs with the red spathe form (Hay, 1998), and our two accessions represented these color morphs.

The A. longiloba species complex comprises seven species from Sundaland und Sulawesi that share unifoliar growth modules and a non-persistent lower spathe during fruit ripening, viz. Alocasia denudata, Alocasia korthalsii, A. longiloba, Alocasia lowii, Alocasia putzeysii, Alocasia thibautiana, and Alocasia watsoniana (Hay, 1998; our Fig. 3). Hay saw them as closely related to Alocasia sanderiana (Philippines), Alocasia boyceana (Philippines), and Alocasia suhirmaniana (Sulawesi). We sampled all these species except $A$. putzeysii and A. thibautiana. The nuclear phylogeny (Fig. 3b) shows that the longiloba group sensu Hay indeed clusters with $A$. sanderiana as he suggested, but also with Alocasia grandis and Alocasia agyrea, which he did not consider part of the longiloba complex. The estimated divergence dates of the relevant species fall in the Pliocene (Fig. 4) and are thus relatively old. Alocasia lowii from Borneo is distinguished by two substitutions in its nuclear phyC-gene from A. watsoniana and $A$. korthalsii, perhaps reflecting beginning speciation. In Sarawak, $A$. lowii is restricted to limestone hills, where $A$. korthalsii and $A$. watsoniana have never been found.

\subsection{Divergence date estimation and the role of dispersal in Alocasia}

The inferred stem age of Alocasia and other ages inside the genus are robust to topological changes in the Pistia clade (Table S2). In the following discussion, we focus on the Alocasia ages obtained under the strict clock model, which on average were younger than those obtained with the relaxed clock. We prefer this model because it uses fewer parameters than the relaxed clock model, reducing the risk of over-parameterization. Diversification in Alocasia apparently began in the Middle Miocene and intensified in the Late Miocene and Pliocene (Fig. 4). Spread from the Asian mainland to the Malesian region can be inferred from the distribution of the relevant outgroups, including the closest living relative of Alocasia, Colocasia gigantea (Fig. 1).

Borneo has played a central role in the geographic expansion of Alocasia. Although only reached 3-4 times, 11-13 of the 18-19 inferred dispersal events originated on Borneo. The Philippines were reached from Borneo 4-5 times in the Late Miocene and Early Pliocene, and the Asian mainland was "recolonized" 6-7 times in the Pliocene. Even though Borneo is the clear center of Alocasia dispersal in the Sunda region, the eastern part of the Malesian Archipelago was colonized from the Philippines. At least one dispersal event occurred from the Philippines to Sulawesi in the late Miocene and a second to New Guinea and Australia at the Miocene/Pliocene boundary, followed by a single recent dispersal from Borneo to Sulawesi. The west to east dispersal of Alocasia with several crossings of the Wallace line started at approximately 5-7 Ma as also found in Aglaieae (Muellner et al., 2008), Pseuduvaria (Su and Saunders, 2009), and Begonia (Thomas et al., 2011). Overall, we inferred at least 10 dispersal events across ocean expanses (light-blue arrows in Fig. 4). Alocasia fruits are red berries, 
$0.3-1 \mathrm{~cm}$ in diameter and dispersed by understory birds, but we know of no field observations on the ecology of dispersal, germination, and seedling establishment. The closest living relative revealed in this study, Colocasia gigantea, produces white fruits that measure only $5 \mathrm{~mm}$ in diameter and are densely packed along an infructescence.

New Guinea is the only region underrepresented in our sampling (Hay and Wise, 1991; cf. Section 2.1). The five New Guinean species included here belong to a morphologically homogeneous group, called Xenophya group (Nicolson, 1968). Of the eight unsampled New Guinean species, two belong to the Xenophya group and six do not (Hay and Wise, 1991). This suggests that New Guinean Alocasia may comprise more independent arrivals than just the one inferred here.

Overall the inferred node ages match the tectonic and climate history of the Malesian region. Collision between the Australian and Eurasian plates started in the Late Oligocene, about $25 \mathrm{Ma}$ ago (Hall, 2002, 2009) and led to island emergence. Mid-Miocene pollen records indicate a warm, moist climate and rainforest expansion on these newly forming islands (Morley, 1998), and groups adapted to rainforest understorey, such as Alocasia, could therefore plausibly spread and diversify. Land bridges repeatedly connected some areas, including New Guinea and Australia on the Sahul shelf, and Indochina, Sumatra, Java, and Borneo on the Sunda shelf. During the last glacial maximum (LGM), sea levels were approximately $120 \mathrm{~m}$ lower than today, resulting in the complete exposure of the Sunda shelf and allowing overland migration between the Asian mainland and Borneo, and even sea level reduction by just $40 \mathrm{~m}$ already connected these islands (Fig. 1, $40 \mathrm{~m}$ isobath). Such sea level lowering occurred several times, mainly in the Pleistocene, but probably also during the Pliocene and the late Miocene (Miller et al., 2005). Whether Alocasia could take advantage of such newly exposed land bridges would have depended on the new biota; savanna vegetation during the LGM on much of the exposed shelf area (as suggested by Bird et al., 2005 and Cannon et al., 2009) would have hindered migration of rainforest-associated Alocasia species. Indeed, of the 24 Alocasia lineage splits that fall into the Pleistocene (Fig. 4), only one involves a range expansion on the Sunda shelf (from Borneo to Asia).

\subsection{Geographic origin of the cultivated species A. cucullata and A. macrorrhizos}

The ornamental Alocasia cucullata (Chinese taro) and the tuber crop A. macrorrhizos (giant taro) have been cultivated for a long time (Boyce, 2008). Starch grains of $A$. macrorrhizos have been found on Solomon Island stone tools dated to 27,000 years before present (Loy et al., 1992). Today, A. cucullata is found in gardens throughout tropical Asia, and A. macrorrhizos throughout the tropics. Neither species has been found far from human settlements (Hay, 1999; Boyce, 2008). Our plastid and nuclear trees place $A$. cucullata close to A. odora and Alocasia navicularis inside an Asian mainland clade (Fig. 3a and b). The inferred recent divergence of these three species (1.31 Ma, 0-2.9 95\% HPD; Fig. 4) and their low sequence divergence ( 6 substitutions in plastid sequences of A. cucullata compared to A. odora, 11 to A. navicularis and one in the nuclear sequences) point to $A$. cucullata being a domesticated form of $A$. odora or $A$. navicularis, which both range from India through Indochina to South China.

Alocasia macrorrhizos groups with Philippine species and is identical in its nuclear sequences with $A$. portei and a plant of unknown origin cultivated in the Bogor Botanical Garden (Alocasia spec. nov. Bo7). Hay (1998) already suspected a Philippine origin of $A$. macrorrhizos and suggested hybridization with $A$. portei.

\section{Conclusions}

The diversification of Alocasia started in the Miocene (at c. 13.5 Ma under a strict clock model or c. 19.3 Ma under a relaxed clock), when the climate changed to warm and humid conditions, which led to the expansion of rainforest in the Malesian region. Exposed land bridges and smaller inter-island distances due to lower sea levels permitted repeated clade expansion from and to Borneo and the Philippines, as well as occasional crossing of the Wallace line to Sulawesi, New Guinea, and Australia. That the plastid tree topology reflects geographic proximity while the nuclear tree more closely matches morphological resemblance, suggests occasional hybridization and local seed dispersal (reflected in the maternal plastid tree) as documented in many other plant genera (Soltis and Kuzoff, 1995; Cannon and Manos, 2003; Bänfer et al., 2006; Cristina Acosta and Premoli, 2010; Manen et al., 2010; Rautenberg et al., 2010). Giant taro, A. macrorrhizos, which is now cultivated in gardens worldwide, originated on the Philippines, while the Chinese taro, A. cucullata, originated on the Asian mainland. More generally, our findings underline the great mobility of plants, the increased recognition of which from dated molecular phylogenies is among the main paradigm shifts in the field of biogeography in recent years.

\section{Acknowledgments}

We are grateful to Josef Bogner for critical comments on the manuscript and to Melanie Medecilo, David Scherberich, David Prehsler, and Alan Elliott for providing samples. Financial support came from the German National Science Foundation (RE 603/11-1).

\section{Appendix A. Supplementary material}

Supplementary data associated with this article can be found, in the online version, at doi:10.1016/j.ympev.2011.12.011.

\section{References}

Bänfer, G., Moog, U., Fiala, B., Mohamed, M., Weising, K., Blattner, F.R., 2006. A chloroplast genealogy of myrmecophytic Macaranga species (Euphorbiaceae) in Southeast Asia reveals hybridization, vicariance and long-distance dispersals. Mol. Ecol. 15, 4409-4424.

Bird, M.I., Taylor, D., Hunt, C., 2005. Palaeoenvironments of insular Southeast Asia during the Last Glacial Period: a savanna corridor in Sundaland? Quaternary Sci. Rev. 24, 2228-2242.

Blume, C.L., 1823. Catalogus van eenige der merkwaardigste zoo in- als uitheemsche gewassen te vinden iv ,s Lands Plantentuin te Buitenzorg/opgemaakt door C.L. Blume. (Reprinted by the Arnold Arboretum, 1946.)

Boyce, P.C., 2008. A review of Alocasia (Araceae: Colocasieae) for Thailand including a novel species and new species' records from S.W. Thailand. Thai Forest Bull. $36,1-17$.

Cabrera, L.I., Salazar, A.G., Chase, M.W., Mayo, S.J., Bogner, J., Davila, P., 2008. Phylogenetic relationships of aroids and duckweeds (Araceae) inferred from coding and noncoding plastid DNA. Am. J. Bot. 95, 1153-1165.

Cannon, C.H., Manos, P.S., 2003. Phylogeography of the Southeast Asian Stone Oaks (Lithocarpus). J. Biogeogr. 30, 211-226.

Cannon, C.H., Morley, R.J., Bush, A.B.G., 2009. The current refugial rainforests of Sundaland are unrepresentative of their biogeographic past and highly vulnerable to disturbance. Proc. Natl. Acad. Sci. USA 106, 11188-11193.

Clark, J.R., Ree, R.H., Alfaro, M.E., King, M.G., Wagner, W.L., Roalson, E.H., 2008. A comparative study in ancestral range reconstruction methods: retracing the uncertain histories of insular lineages. Syst. Biol. 57, 693-707.

Crisp, M.D., Isagi, Y., Kato, Y., Cook, L.G., Bowman, D.M.J.S., 2010. Livistona palms in Australia: ancient relics or opportunistic immigrants? Mol. Phylogenet. Evol. 54, 512-523.

Cristina Acosta, M., Premoli, A.C., 2010. Evidence of chloroplast capture in South American Nothofagus (subgenus Nothofagus, Nothofagaceae). Mol. Phylogenet. Evol. 54, 235-242.

Cusimano, N., Bogner, J., Mayo, S.J., Boyce, P.C., Wong, S.Y., Hesse, M., Hetterscheidt W.L.A., Keating, R.C., French, J.C., 2011. Relationships within the Araceae: Comparisons of morphological patterns with molecular phylogenies. Am. J. Bot. 98, 1-15.

Drummond, A.J., Rambaut, A., 2007. BEAST: Bayesian evolutionary analysis by sampling trees. BMC Evol. Biol. 7, 214. 
Drummond, A.J., Ho, S.Y.W., Phillips, M.J., Rambaut, A., 2006. Relaxed phylogenetics and dating with confidence. PLoS Biol. 4, e88.

Friis, E.M., Raunsgaard, K.P., Crane, P.R., 2004. Araceae from the Early Cretaceous of Portugal: evidence on the emergence of monocotyledons. PNAS 101, 1656516570.

Friis, E.M., Pedersen, K.R., Crane, P.R., 2010. Diversity in obscurity: fossil flowers and the early history of angiosperms. Philos. Trans. Roy. Soc. Lond. [Biol.] 365, 369382.

Garner, L., 2010. Alocasia zebrina and two allies-a case study. Aroideana 33, 212214.

Hall, R., 2002. Cenozoic geological and plate tectonic evolution of SE Asia and the SW Pacific: computer-based reconstructions, model and animations. J. Asian Earth Sci. 20, 353-431.

Hall, R., 2009. Southeast Asia's changing palaeogeography. Blumea 54, 148-161.

Hay, A., 1998. The genus Alocasia (Araceae-Colocasieae) in west Malesia and Sulawesi. Gard. Bull. Sing. 50, 221-334.

Hay, A., 1999. The genus Alocasia (Araceae-Colocasieae) in the Philippines. Gard. Bull. Sing. 51, 1-41.

Hay, A., Wise, R., 1991. The genus Alocasia (Araceae) in Australasia. Blumea 35, 495499.

Herrera, F.A., Jaramillo, C.A., Dilcher, D.L., Wing, S.L., Gomez-N, C., 2008. Fossil Araceae from a Paleocene Neotropical rainforest in Colombia. Am. J. Bot. 95, 1569-1583.

Hooker, J.D., 1893. Aroideae. Flora of British India, vol. 6. London.

Ivancic, A., Roupsard, O., Garcia, J.Q., Lebot, V., Pochyla, V., Okpul, T., 2005 Thermogenic flowering of the giant taro (Alocasia macrorrhizos, Araceae). Can. J. Bot. 83, 647-655.

Ivancic, A., Roupsard, O., Garcia, J.Q., Melteras, M., Molisale, T., Tara, S., Lebot, V. 2008. Thermogenesis and flowering biology of Colocasia gigantea. Araceae. J. Plant Res. 121, 73-82.

Johnson, L.A., Soltis, D.E., 1994. MatK DNA sequences and phylogenetic reconstruction in Saxifragaceae s. str. Syst. Bot. 19, 143-156.

Kurniawan, A., Boyce, P., 2011. Studies on Alocasia Schott (Araceae-Colocasieae) of Borneo II: Alocasia baginda, a new species from Eastern Kalimantan, Indonesian Borneo. Acta Phytotax. Geobot. 60, 123-126.

Lohman, D.J., de Bruyn, M., Page, T., von Rintelen, K., Hall, R., Ng, P.K.L., Shih, H.-T. Carvalho, G.R., von Rintelen, T., 2011. Biogeography of the Indo-Australian archipelago. Annu. Rev. Ecol. Evol. Syst. 42, 205-226, doi:10.1146/annurevecolsys-102710-145001.

Loy, T., Spriggs, M., Wickler, S., 1992. Direct evidence for human use of plants 28,000 years ago: starch residues on stone artifacts from the northern Solomon Islands. Antiquity 66, 898-912.

Maddison, W.R., Maddison, W.P., 2000. MacClade. Version 4.0. Sinauer Associates, Sunderland, Massachusetts, USA

Manen, J.F., Barriera, G., Loizeau, P.A., Naciri, Y., 2010. The history of extant Ilex species (Aquifoliaceae): evidence of hybridization within a Miocene radiation. MPE 57, 961-977.

Mayo, S.J., Bogner, J., Boyce, P.C., 1997. The Genera of Araceae. Kew: Royal Botanical Gardens, London, UK.

Miller, K.G., Kominz, M.A., Browning, J.V., Wright, J.D., Mountain, G.S., Katz, M.E., Sugarman, P.J., Cramer, B.S., Christie-Blick, N., Pekar, S.F., 2005. The Phanerozoic record of global sea-level change. Science 310, 1293-1298.

Morley, R.J., 1998. Palynological Evidence for Tertiary Plant Dispersal in the SE Asian Region in Relation to Plate Tectonics and Climate. Biogeography and Geologica Evolution of SE Asia. Blackhuys Publishers, Leiden, pp. 211-234.

Muellner, A.N., Pannell, C.M., Coleman, A., Chase, M.W., 2008. The origin and evolution of Indomalesian, Australasian and Pacific island biotas: insights from Aglaieae (Meliaceae, Sapindales). J. Biogeogr. 35, 1769-1789.

Nicolson, D.H., 1968. The genus Xenophya Schott (Araceae). Blumea 16, 115-118.

Nicolson, D.H., 1987. Araceae. In: Flora of Ceylon, vol. 6. Amerind, New Delhi, India pp. $17-101$.

Posada, D., 2008. jModelTest: phylogenetic model averaging. Mol. Biol. Evol. 25, 1253-1256.
Rautenberg, A., Hathaway, L., Oxelman, B., Prentice, H.C., 2010. Geographic and phylogenetic patterns in Silene section Melandrium (Caryophyllaceae) as inferred from chloroplast and nuclear DNA sequences. Mol. Phylogenet. Evol. 57, 978-991.

Ree, R., Smith, S., 2008. Maximum likelihood inference of geographic range evolution by dispersal, local extinction, and cladogenesis. Syst. Bot. 57, 414.

Ree, R., Moore, B.R., Webb, C.O., Donoghue, M.T., 2005. A likelihood framework for inferring the evolution of geographic range on phylogenetic trees. Evolution 59, 2299-2311.

Renner, S.S., Zhang, L.B., 2004. Biogeography of the Pistia Clade (Araceae): based on chloroplast and mitochondrial DNA sequences and Bayesian divergence time inference. Syst. Biol. 53, 422-432.

Richardson, J.E., Costion, C.M., Muellner, A.N., 2012. The Malesian Floristic Interchange: plant migration patterns across Wallace's Line. In: Gower, D., Johnson, K., Richardson, J.E., Rosen, B., Rüber, L., Williams, S. (Eds.), Biotic Evolution and Environmental Change in Southeast Asia. Cambridge University Press, UK.

Ronquist, F., 1997. Dispersal-Vicariance Analysis: a new approach to the quantification of historical biogeography. Syst. Biol. 46, 195-203.

Schott, H.W., 1857. Leucocasia, eine Gattung der Colocasinae. Oesterr. Bot. Wochenbl. 7, 33-35.

Silvestro, D., Michalak, I., 2010. raxmlGUI: a graphical front-end for RAxML. <http:// sourceforge.net/projects/raxmlgui/>.

Soltis, D.E., Kuzoff, R.K., 1995. Discordance between nuclear and chloroplast phylogenies in the Heuchera group (Saxifragaceae). Evolution 49, 727742 .

Stamatakis, A., 2006. RAxML-VI-HPC: maximum likelihood-based phylogenetic analyses with thousands of taxa and mixed models. Bioinformatics 22, 26882690

Su, Y.C.F., Saunders, R.M.K., 2009. Evolutionary divergence times in the Annonaceae: evidence of the late Miocene origin of Pseuduvaria in Sundaland with subsequent diversification in New Guinea. BMC Evol. Biol. 9, 153.

Sultana, F., Hu, Y.G., Toda, M.J., Takenaka, K., Yafuso, M., 2006. Phylogeny and classification of Colocasiomyia (Diptera, Drosophilidae), and its evolution of pollination mutualism with aroid plants. Syst. Entomol. 31, 684-702.

Taberlet, P., Gielly, L., Pautou, G., Bouvet, J., 1991. Universal primers for amplification of three non-coding regions of chloroplast DNA. Plant Mol. Biol. 17, 1105-1109.

Thomas, D.C., Hughes, M., Phutthai, T., Ardi, W.H., Rajbhandary, S., Rubite, R., Twyford, A.D., Richardson, J.E., 2011. West to east dispersal and subsequent rapid diversification of the mega-diverse genus Begonia (Begoniaceae) in the Malesian archipelago. J. Biogeogr.. doi:10.1111/j.1365-2699.2011.02596.x.

Toda, M.J., Lakim, M.B., 2011. The genus Colocasiomyia (Drosophilidae: Diptera) in Sabah, Bornean Malaysia: high species diversity and use of host aroid inflorescences. Entomol. Sci. 14, 262-270.

Walker, J.D., Geissman, J.W., compilers, 2009. Geologic Time Scale: Geological Society of America. doi:10.1130/2009.

Wallace, A.R., 1869. The Malay Archipelago: The Land of the Oran-Utan, and the Bird of Paradise. A Narrative of Travel, with Studies of Man and Nature. Harper and Brothers, New York, USA.

Wang, Y.H., Yin, J.T., Xu, Z.F., 2005. Alocasia hypnosa (Araceae), a new species from Yunnan, China. Ann. Bot. Fenn. 42, 395-398.

Weightman, B., 1989. Agriculture in Vanuatu. A Historical Review. The British Friends of Vanuatu, Portsmouth, UK.

Wilde, V., Kvacek, Z., Bogner, J., 2005. Fossil leaves of the Araceae from the European Eocene and notes on other aroid fossils. Int. J. Plant Sci. 166, 157-183.

Yu, Y., Harris, A.J., He, X., 2010. S-DIVA (Statistical Dispersal-Vicariance Analysis): a tool for inferring biogeographic histories. Mol. Phylogenet. Evol. 56, 848850.

Yu, Y., Harris, A.J., He, X., 2011. RASP (Reconstruct Ancestral State in Phylogenies) [vs1.1]. <http://mnh.scu.edu.cn/soft/blog/RASP>. 